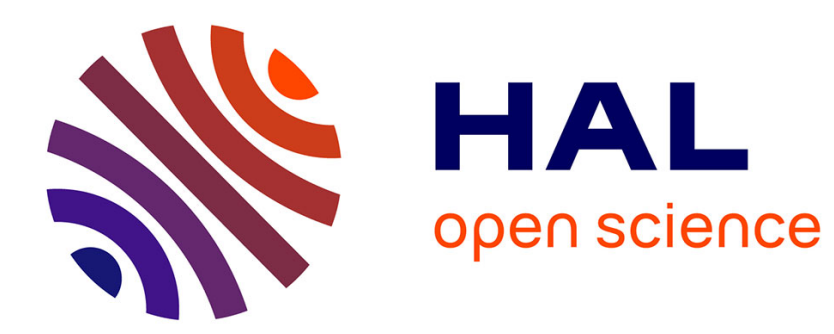

\title{
Pollution, Unequal Lifetimes and Fairness
}

Grégory Ponthière

\section{To cite this version:}

Grégory Ponthière. Pollution, Unequal Lifetimes and Fairness. 2014. hal-01095463

\section{HAL Id: hal-01095463 \\ https://hal-pjse.archives-ouvertes.fr/hal-01095463}

Preprint submitted on 15 Dec 2014

HAL is a multi-disciplinary open access archive for the deposit and dissemination of scientific research documents, whether they are published or not. The documents may come from teaching and research institutions in France or abroad, or from public or private research centers.
L'archive ouverte pluridisciplinaire HAL, est destinée au dépôt et à la diffusion de documents scientifiques de niveau recherche, publiés ou non, émanant des établissements d'enseignement et de recherche français ou étrangers, des laboratoires publics ou privés. 


\section{PARISSCHOOL OF ECONOMICS}

WORKING PAPER Nº 2014 - 41

Pollution, Unequal Lifetimes and Fairness

Grégory Ponthière

JEL Codes: E13, E21, I31, Q50

Keywords: pollution, mortality, OLG model, fairness

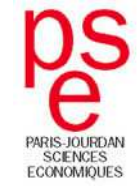




\title{
Pollution, Unequal Lifetimes and Fairness*
}

\author{
Gregory Ponthiere ${ }^{\dagger \ddagger}$
}

December 5, 2014

\begin{abstract}
Pollution is a major cause of mortality, leading to substantial inequalities in lifetime well-being across individuals. This paper characterizes the optimal level of pollution in a two-period OLG economy where pollution deteriorates survival conditions. We compare two long-run social optima: on the one hand, the average utilitarian optimum, where the long-run average well-being is maximized, and, on the other hand, the ex post egalitarian optimum, where the well-being of the worst-off at the stationary equilibrium is maximized. It is shown that the ex post egalitarian optimum involves a higher level of pollution in comparison with the utilitarian optimum. This result is robust to introducing health expenditures in the survival function. Finally, we examine the decentralization of those two social optima, and we compare the associated optimal taxes on capital income aimed at internalizing the pollution externality.

Keywords: pollution, mortality, OLG model, fairness.

JEL classification codes: E13, E21, I31, Q50,
\end{abstract}

${ }^{*}$ The author would like to thank Arnold Chassagnon and Fabrice Etilé for their helpful comments on this paper.

${ }^{\dagger}$ University Paris East (ERUDITE) and Paris School of Economics. Address: ENS, 48 boulevard Jourdan, 75014 Paris. Building A, Office 201. Telephone: 0033-0143136302. Email: gregory.ponthiere@ens.fr

${ }^{\ddagger}$ The author acknowledges the financial support of ANR EQUIRISK - Equity in Risky Intertemporal Economic Environments - (ANR-12-INEG-0006-01). 


\section{Introduction}

Environmental pollution is a major cause of mortality around the world. Various aspects of the environment affect mortality outcomes, including air pollution, water pollution and soil pollution. ${ }^{1}$ The impact of environmental quality on human longevity can be illustrated by the significant overmortality due to air pollution. According to a recent study by WHO (2014), about 7 million deaths can be imputed, around the world, to (indoor and outdoor) air pollution in 2012. A large proportion of premature deaths due to air pollution take place in urban areas around the developing world. ${ }^{2}$

Following the empirical evidence supporting the existence of an environmental Kuznetz curve (Grossman and Krueger 1995), the theory of long-run economic growth has progressively taken pollution into account. ${ }^{3}$ Within the overlapping generations (OLG) setting, the introduction of pollution is due to John and Pecchenino (1994) and John et al (1995). In those models, capital accumulation does not only influence the consumption possibilities of future generations: it also affects the quality of the natural environment. Following those works, various OLG models studied the growth/pollution relationship and the optimal public intervention in that context. ${ }^{4}$

Whereas those OLG models assumed a fixed lifetime, a strong emphasis was recently laid, within OLG models, on the influence of pollution on mortality. The impact of pollution on survival conditions introduces a feedback mechanism in the modeling of economic dynamics. If pollution deteriorates life expectancy, this is likely to lead to lower savings, to lower capital, and, in fine, to lower future pollution levels, which, in turn, will improve future survival prospects. Hence, making survival conditions dependent on pollution complicates long-run dynamics (see Mariani et al 2010, Balestra and Dottori 2012).

Besides the study of long-run dynamics, the pollution/mortality relationship raises also deep challenges for policy-makers. As studied by Jouvet et al (2010) in an OLG model where pollution reduces (certain) longevity, the internalization of pollution externalities requires the design of appropriate fiscal instruments (i.e. Pigouvian taxes). But internalizing externalities is not the only goal of public policy in the presence of pollution. Actually, in real life, pollution is not only a source of externalities, it is also a cause of large inequalities in longevity. Because of pollution, some individuals turn out to have shorter lives, whereas other individuals can still enjoy a long life. As a consequence, longevity inequalities due to pollution generate large inequalities in lifetime well-being.

What should governments do in front of those inequalities? To answer that question, let us consider Fleurbaey's theory of fairness (Fleurbaey 2008). Fleurbaey distinguishes between two kinds of inequalities: on the one hand, inequalities due to circumstances (on which individuals have no control), and, on the

\footnotetext{
${ }^{1} \mathrm{On}$ the various effects of environmental quality on human longevity, see Sartor (2002).

${ }^{2}$ Other important studies on the impact of air pollution on mortality include Kinney and Ozkanyak (1991), Finkelstein et al (2003), Peng et al (2005), and Laden et al (2006).

${ }^{3}$ For a survey on the environmental Kuznetz curve, see Dinda (2004).

${ }^{4}$ See Jouvet et al (2000), Ono (2002), Jouvet el al (2005), and Nakabayashi (2010).
} 
other hand, inequalities due to responsibility variables (on which individuals have some control). According to Fleurbaey's Principle of Compensation, inequalities due to circumstances should be abolished. The Principle of Compensation is most relevant for longevity inequalities due to pollution. Indeed, given that survival conditions often depend on the aggregate level of pollution, and given that each individual has, on his own, little control on the aggregate pollution level, pollution victims can hardly be regarded as responsible for their premature death. Hence the question of their compensation matters.

Standard normative criteria such as utilitarianism cannot, in general, justify the compensation of pollution victims. As it is well-known, utilitarianism makes sense when the population under study is homogeneous. ${ }^{5}$ However, once we consider a population where individuals differ on fundamental aspects (affecting their capacity to convert resources into well-being), the utilitarian criterion often leads to a counterintuitive treatment of disadvantaged individuals. ${ }^{6}$ At the utilitarian social optimum, there remain, in general, large inequalities in realized lifetime well-being across individuals having unequal lifetimes. However, when those inequalities are due to circumstances, there is a strong motivation for compensating those short-lived persons. This intuition motivated the development of alternative normative criteria aimed at minimizing inequalities in realized lifetime well-being between short-lived and long-lived individuals (see Fleurbaey and Ponthiere 2013 and Fleurbaey et al 2014).

This paper aims at examining the compensation of pollution victims. For that purpose, we will first compare the optimal pollution level under two social optima: on the one hand, the average utilitarian optimum, where the long-run average well-being is maximized, and, on the other hand, the ex post egalitarian optimum, where the well-being of the worst-off at the stationary equilibrium is maximized. Then, we will examine the decentralization of those two social optima by means of fiscal instruments. That comparison will allow us to assess the robustness of the optimal policy to the underlying social welfare function, by comparing the optimal policies under those social objectives.

For that purpose, we consider a two-period OLG economy with physical capital accumulation, where production generates some pollution, which, in turn, reduces life expectancy. Our normative analysis consists of a long-run analysis: we examine what kind of stationary equilibrium would be selected under the two social welfare functions under comparison. Similarly, our policy analysis is a long-run policy analysis: we consider the fiscal instruments required for the decentralization of the long-run social optima under study.

Anticipating our results, we show that the ex post egalitarian optimum involves a higher level of pollution in comparison with the average utilitarian optimum. This result is robust to introducing health expenditures in the sur-

\footnotetext{
${ }^{5}$ This is the case in Jouvet et al (2010), where pollution affects the duration of the old age lived by all members of a cohort.

${ }^{6}$ Those limits were emphasized, in different contexts, by Arrow (1971), Sen (1973) and Mirrlees (1982). If, for instance, handicapped persons exhibit a lower capacity to convert resources into well-being, utilitarianism will penalize them, by allocating fewer resources to them. But many would argue that we should give not less, but more resources to the handicapped.
} 
vival function. When examining the decentralization of those two social optima, we compare the associated optimal taxes on capital income aimed at internalizing the pollution externality, and we show that the optimal taxes on capital income obtained under those two optima differ strongly, to an extent that depends on the shape of individual preferences and on the form of the survival process. The decentralization of the ex post egalitarian optimum requires, in general, a higher tax on capital income than under utilitarianism, but that tax is decreasing with the extent to which pollution affects survival conditions (unlike under utilitarianism). Thus, the design of the optimal environmental policy is strongly sensitive to the underlying social objective, and, in particular, to the attention paid to the compensation of the short-lived.

The rest of the paper is organized as follows. Section 2 presents the model of a simple OLG economy with pollution and risky lifetime. The utilitarian social optimum is characterized in Section 3. Section 4 derives the ex post egalitarian social optimum, and compares it with the utilitarian optimum. Section 5 examines the robustness of the differences between the two social optima to the introduction of health expenditures as an input in the survival function. Then, Section 6 considers the decentralization of the two social optima, and compare the associated optimal public policies. Conclusions are drawn in Section 7.

\section{The model}

We consider an OLG economy with pollution and risky lifetime. Time is discrete and goes from 0 to infinity. All cohorts are, at birth, of size $N>0$. Longevity is risky: all individuals live the first period, during which they work, save and consume, but only some fraction of each cohort will survive to the second period, and enjoy the retirement period.

Survival conditions All individuals born at time $t$ live the first period for sure, but only a fraction $\pi_{t+1}$ of that cohort will survive to the second period. The proportion of survivors depends on the level of pollution at period $t$ :

$$
\pi_{t+1}=\pi\left(P_{t}\right)
$$

We assume, as usual, that $0<\pi_{t+1}<1 \forall P_{t}>0$, and that $\pi^{\prime}\left(P_{t+1}\right)<0$ and $\pi^{\prime \prime}\left(P_{t+1}\right)<0$.

Production The production process involves capital $K_{t}$ and labour $L_{t}$, according to the following production function:

$$
Y_{t}=F\left(K_{t}, L_{t}\right)
$$

where $Y_{t}$ denotes the output at time $t, K_{t}$ is the stock of capital, and $L_{t}$ is the

labour force. Given that only young individuals work, and given that the size of each cohort is, at birth, identical, we have $L_{t}=N \forall t$. As usual, we assume that 
the production function $F(\cdot)$ is positively valued, and is increasing and strictly concave with respect to capital. Capital depreciates at a rate $\delta$.

Assuming constant returns to scale, the production function can be written as:

$$
y_{t}=f\left(k_{t}\right)
$$

where $y_{t} \equiv \frac{Y_{t}}{N}$ is the output per worker, $f\left(k_{t}\right) \equiv F\left(k_{t}, 1\right)$ is the production function in intensive terms, and $k_{t} \equiv \frac{K_{t}}{N}$ is the capital per worker. As examined in de la Croix and Michel (2002), the production function $f\left(k_{t}\right)$ satisfies the properties: $f^{\prime}\left(k_{t}\right)>0$ and $f^{\prime \prime}\left(k_{t}\right)<0$.

Pollution The production process generates some pollution. Polluting emissions $E_{t}$ are proportional to the total output: ${ }^{7}$

$$
E_{t}=\eta F\left(K_{t}, L_{t}\right)
$$

where $\eta>0$ captures the extent to which the production process leads to polluting emissions.

The dynamics of pollution is given by the equation:

$$
P_{t}=E_{t}+(1-\gamma) P_{t-1}
$$

where $0 \leq \gamma \leq 1$ is the natural rate of pollution absorption.

Preferences Individuals have time-additive lifetime well-being, which depends on consumption per period. As usual, the utility of being dead is normalized to 0 . Hence, the lifetime well-being of short-lived individuals in cohort $t$ is:

$$
U_{t}^{s l}=u\left(c_{t}\right)
$$

where $c_{t}$ denotes the consumption at the young age for an individual in cohort $t$. We assume, as usual, that $u^{\prime}(\cdot)>0$ and $u^{\prime \prime}(\cdot)<0$.

For individuals in cohort $t$ who turn out to be long-lived, lifetime well-being is equal to:

$$
U_{t}^{l l}=u\left(c_{t}\right)+u\left(d_{t+1}\right)
$$

where $d_{t+1}$ denotes the second-period consumption.

Following the existing literature (see Becker et al 2005), we assume that there exists a non-negative consumption level that is neutral for the continuation of existence. That neutral consumption level, denoted by $\bar{c}$, is such that $u(\bar{c})=0$.

Resource constraint At any point in time, the consumption and investment in the economy must be equal to the production:

$$
F\left(K_{t}, L_{t}\right)=c_{t} L_{t}+d_{t} \pi\left(P_{t-1}\right) L_{t-1}+K_{t+1}-(1-\delta) K_{t}
$$

The pollution level affects the resource constraint through the survival process $\pi\left(P_{t-1}\right)$. A low $P_{t-1}$ leads to a higher proportion of individuals reaching the retirement period, and, hence, leads to a stronger pressure on available resources.

\footnotetext{
${ }^{7}$ On alternative ways to model pollution, see John and Pecchenino (1994) and John et al (1995).
} 


\section{The utilitarian optimum}

In order to characterize the utilitarian optimum, we will concentrate on a stationary equilibrium. Given that the size of cohorts at birth is constant over time, and equal to $N$, a stationary equilibrium consists here of a situation where all variables - both in levels and in per worker terms - are constant over time.

Imposing $P_{t}=P_{t-1}$ in the pollution dynamics equation yields the following stationary pollution stock:

$$
P=\frac{\eta F(K, L)}{\gamma}=\frac{\eta N f(k)}{\gamma}
$$

where $k$ denotes the stationary capital per worker.

Moreover, the resource constraint becomes, at the stationary equilibrium:

$$
F(K, N)=c N+d \pi(P) N+K-(1-\delta) K
$$

When rewritten in intensive terms, that expression becomes:

$$
f(k)-\delta k=c+d \pi(P)
$$

In the light of this, the utilitarian social planner's problem can be represented as the selection of levels of consumptions, capital and pollution that maximize average lifetime well-being at the stationary equilibrium, subject to the resource constraint of the economy and subject to the stationary pollution level:

$$
\begin{aligned}
& \max _{c, d, k, P} u(c)+\pi(P) u(d) \\
& \text { s.t. } f(k)-\delta k=c+d \pi(P) \\
& \text { s.t. } P=\frac{\eta N f(k)}{\gamma}
\end{aligned}
$$

Given that $P$ is a function of $k$, that problem can be rewritten as the selection of variables $\{c, d, k\}$ maximizing average lifetime well-being subject to the resource constraint of the economy. That problem can be rewritten by means of the following Lagrangian:

$$
\max _{c, d, k} u(c)+\pi\left(\frac{\eta N f(k)}{\gamma}\right) u(d)+\lambda\left[f(k)-\delta k-c-d \pi\left(\frac{\eta N f(k)}{\gamma}\right)\right]
$$

where $\lambda$ is the Lagrange multiplier associated to the resource constraint. The first order conditions (FOCs) can be rewritten as:

$$
\begin{aligned}
u^{\prime}(c) & =u^{\prime}(d) \\
f^{\prime}(k) & =\delta-\pi^{\prime}\left(\frac{\eta N f(k)}{\gamma}\right) \frac{\eta N f^{\prime}(k)}{\gamma} \frac{\left[u(d)-d u^{\prime}(d)\right]}{u^{\prime}(d)}
\end{aligned}
$$

as well as the conditions:

$$
\lambda \geq 0, f(k)-\delta k \geq c+d \pi\left(\frac{\eta N f(k)}{\gamma}\right)
$$


with complementary slackness.

As stated in condition (12), the utilitarian optimum involves smoothed consumption profiles along the lifecycle. Regarding the optimal capital, the condition (13) is a modified version of the standard Golden Rule for optimal capital accumulation (Phelps 1961). In standard OLG models without pollution, we have $\pi^{\prime}(\cdot)=0$, and the condition for optimal capital is:

$$
f^{\prime}(k)=\delta
$$

However, in our model, capital accumulation tends to deteriorate survival chances (i.e. $\pi^{\prime}(\cdot)<0$ ), with the consequence that a second term is added on the right-hand side (RHS) of the Golden Rule condition. That term, equal to:

$$
-\pi^{\prime}\left(\frac{\eta N f(k)}{\gamma}\right) \frac{\eta N f^{\prime}(k)}{\gamma} \frac{\left[u(d)-d u^{\prime}(d)\right]}{u^{\prime}(d)}
$$

is positive if and only if

$$
u(d)-d u^{\prime}(d)>0
$$

That condition states that the marginal welfare gain from a higher survival probability, i.e. $u(d)$, must be higher, at the social optimum, than the marginal welfare loss from a higher survival probability, i.e. $d u^{\prime}(d){ }^{8}$

Whether $u(d)$ is superior to $d u^{\prime}(d)$ or not depends on several aspects of the economy. First of all, it depends on the shape of the utility function $u(\cdot)$. When $u(\cdot)$ satisfies $u(0) \geq 0$, it is always the case, given the concavity of $u(\cdot)$, that $u(d)$ is superior to $d u^{\prime}(d)$. However, we assume here that there exists $\bar{c}>0$ such that $u(\bar{c})=0$, so that $u(0)<0$. Hence we cannot rely only on the mere concavity of $u(\cdot)$ to know whether $u(d)-d u^{\prime}(d) \gtrless 0$.

Actually, under $u(0)<0$, whether $u(d)-d u^{\prime}(d) \gtrless 0$ depends on the level of $d$, which is determined by the shape of the production function $f(k)$. If the production process brings high output levels, consumption levels are high, and so it is likely that $u(d)$ is high and $u^{\prime}(d)$ is low, leading to $u(d)-d u^{\prime}(d)>0$. On the contrary, if the production process is not efficient, output and consumption levels are low, leading potentially to $d<\bar{c}$, implying that $u(d)<d u^{\prime}(d)$. That case coincides with an economy having a low production capacity, and where consumption levels are below the threshold $\bar{c}$ making a life-period enjoyable.

In sum, two cases can arise. If the production capacity is sufficiently efficient, the socially optimal second-period consumption is sufficiently high to guarantee $u(d)-d u^{\prime}(d)>0$. As a consequence, the optimal $k$ is here lower than in the absence of pollution. If, on the contrary, the production capacity is not efficient, the optimal $d$ is so low that $u(d)-d u^{\prime}(d)<0$. Hence, in that case, the optimal $k$ is here higher than under the standard Golden Rule (i.e. in the absence of pollution). Proposition 1 summarizes our results.

\footnotetext{
${ }^{8}$ Alternatively, that condition can be rewritten as:

$$
\frac{u^{\prime}(d)}{u(d)}<\frac{1}{d}
$$

where the LHS is the fear of ruin, a measure of risk aversion.
} 
Proposition 1 If

$$
\lim _{k \rightarrow+\infty} f^{\prime}(k)=0
$$

and if

$$
\lim _{k \rightarrow 0} f^{\prime}(k)\left[1+\pi^{\prime}\left(\frac{\eta N f(0)}{\gamma}\right) \frac{\eta N}{\gamma} \frac{u\left(\frac{f(0)}{1+\pi\left(\frac{\eta N f(0)}{\gamma}\right)}\right)-\frac{f(0) u^{\prime}\left(\frac{f(0)}{1+\pi\left(\frac{\eta N f(0)}{\gamma}\right)}\right)}{1+\pi\left(\frac{\eta N f(0)}{\gamma}\right)}}{u^{\prime}\left(\frac{f(0)}{1+\pi\left(\frac{\eta N f(0)}{\gamma}\right)}\right)}\right]>\delta
$$

an interior utilitarian social optimum $\left\{c_{u}, d_{u}, k_{u}, P_{u}\right\}$ exists and satisfies:

$$
\begin{aligned}
c_{u} & =d_{u} \\
f^{\prime}\left(k_{u}\right) & =\delta-\pi^{\prime}\left(P_{u}\right) \frac{\eta N f^{\prime}\left(k_{u}\right)}{\gamma} \frac{\left[u\left(d_{u}\right)-d_{u} u^{\prime}\left(d_{u}\right)\right]}{u^{\prime}\left(d_{u}\right)} \\
P_{u} & =\frac{\eta N f\left(k_{u}\right)}{\gamma} \\
f\left(k_{u}\right)-\delta k_{u} & =c_{u}+d_{u} \pi\left(P_{u}\right)
\end{aligned}
$$

If $u\left(d_{u}\right)-d_{u} u^{\prime}\left(d_{u}\right)>0$ (resp. <0), we have $k_{u}$ lower (resp. higher) than under the standard Golden Rule $\left(\pi^{\prime}(\cdot)=0\right)$.

Proof. Let us rewrite the FOC for optimal capital as:

$$
f^{\prime}(k)\left[1+\pi^{\prime}\left(\frac{\eta N f(k)}{\gamma}\right) \frac{\eta N}{\gamma} \frac{\left[u(d)-d u^{\prime}(d)\right]}{u^{\prime}(d)}\right]=\delta
$$

Using $d=d_{u}=\frac{f(k)-\delta k}{1+\pi\left(\frac{\eta N f(k)}{\gamma}\right)}$, we can rewrite the LHS as:

$$
\phi(k)=f^{\prime}(k)\left[1+\pi^{\prime}(\cdot) \frac{\eta N}{\gamma} \frac{\left[u\left(\frac{f(k)-\delta k}{1+\pi\left(\frac{\eta N f(k)}{\gamma}\right)}\right)-\frac{f(k)-\delta k}{1+\pi(\cdot)} u^{\prime}\left(\frac{f(k)-\delta k}{1+\pi(\cdot)}\right)\right]}{u^{\prime}\left(\frac{f(k)-\delta k}{1+\pi(\cdot)}\right)}\right]
$$

Suppose that $\lim _{k \rightarrow+\infty} f^{\prime}(k)=0$. Then, we have:

$\lim _{k \rightarrow+\infty} \phi(k)=0 \lim _{k \rightarrow+\infty}\left[1+\pi^{\prime}(\cdot) \frac{\eta N}{\gamma} \frac{\left[u\left(\frac{f(k)-\delta k}{1+\pi(\cdot)}\right)-\frac{f(k)-\delta k}{1+\pi(\cdot)} u^{\prime}\left(\frac{f(k)-\delta k}{1+\pi(\cdot)}\right)\right]}{u^{\prime}\left(\frac{f(k)-\delta k}{1+\pi(\cdot)}\right)}\right]=0$

Thus, when $k \rightarrow+\infty$, we have $\phi(k)<\delta$.

Consider now the case where $k$ tends towards 0 . The uniqueness of the equilibrium requires that $\phi(k)$ is now larger than $\delta$. This is achieved when:

$\lim _{k \rightarrow 0} f^{\prime}(k)\left[1+\pi^{\prime}\left(\frac{\eta N f(0)}{\gamma}\right) \frac{\eta N}{\gamma} \frac{\left[u\left(\frac{f(0)}{1+\pi\left(\frac{\eta N f(0)}{\gamma}\right)}\right)-\frac{f(0)}{1+\pi\left(\frac{\eta N f(0)}{\gamma}\right)} u^{\prime}\left(\frac{f(0)}{1+\pi\left(\frac{\eta N f(0)}{\gamma}\right)}\right)\right]}{u^{\prime}\left(\frac{f(0)}{1+\pi\left(\frac{\eta N f(0)}{\gamma}\right)}\right)}\right]>\delta$ 
Under that condition, $\phi(k)>\delta$ when $k \rightarrow 0$ and $\phi(k)<\delta$ when $k \rightarrow+\infty$. Hence there must exist, under that condition, some level of $k$ such that $\phi(k)=\delta$. Thus there exists (at least) one interior optimal level of $k$ satisfying the FOC. Once that level of $k$ is known, the above FOCs can be used to derive the optimal levels of $c, d$ and $P$.

The utilitarian optimum involves flat consumption profiles along the lifecycle, as well as a level of capital per worker lower than under the traditional Golden Rule. This latter feature is the mere corollary of the presence of pollution. In our model, capital accumulation affects long-run average lifetime welfare not only through its impact on long-run consumption possibilities (as in the standard Golden Rule), but, also, it leads to pollution, which reduces survival chances. Assuming $u\left(d_{u}\right)-d_{u} u^{\prime}\left(d_{u}\right)>0$, this deterioration of survival conditions affects negatively the long-run average lifetime welfare. Hence, the optimal $k$ must be here lower than in the absence of pollution.

Proposition 1 only states the conditions under which there exists some interior levels of $c, d$ and $k$ satisfying the optimality conditions associated with the utilitarian social planning problem. However, those optimality conditions may be satisfied by several quartets $\{c, d, k, P\}$. Indeed, there may exist several local maxima of steady-state average lifetime well-being. Only one of these local maxima would be the global maximum, at which steady-state average lifetime well-being is the highest. Hence, the conditions stated in Proposition 1 may not be sufficient to fully identify the utilitarian social optimum. This raises the following question: is there a unique quartet $\{c, d, k, P\}$ satisfying the conditions stated in Proposition 1, or are there several quartets $\{c, d, k, P\}$ satisfying those conditions? Proposition 2 examines that issue.

Proposition 2 Suppose that, for all $k>0$, we have:

$$
\begin{aligned}
& f^{\prime \prime}(k)+f^{\prime \prime}(k) \pi^{\prime}\left(\frac{\eta N f(k)}{\gamma}\right) \frac{\eta N \Lambda}{\gamma} \\
& +f^{\prime}(k)\left[\pi^{\prime \prime}\left(\frac{\eta N f(k)}{\gamma}\right) \frac{\eta N f^{\prime}(k)}{\gamma} \frac{\eta N \Lambda}{\gamma}+\pi^{\prime}\left(\frac{\eta N f(k)}{\gamma}\right) \frac{\eta N}{\gamma} \frac{d \Lambda}{d k}\right] \\
< & 0
\end{aligned}
$$

with

$$
\Lambda \equiv \frac{u\left(\frac{f(k)-\delta k}{1+\pi\left(\frac{\eta N f(k)}{\gamma}\right)}\right)-\frac{f(k)-\delta k}{1+\pi\left(\frac{\eta N f(k)}{\gamma}\right)} u^{\prime}\left(\frac{f(k)-\delta k}{1+\pi\left(\frac{\eta N f(k)}{\gamma}\right)}\right)}{u^{\prime}\left(\frac{f(k)-\delta k}{1+\pi\left(\frac{\eta N f(k)}{\gamma}\right)}\right)}
$$

Then, there exists a unique quartet $\left\{c_{u}, d_{u}, k_{u}, P_{u}\right\}$ satisfying the conditions associated with the utilitarian social optimum. 
Proof. The condition for optimal capital is:

$$
\phi(k) \equiv f^{\prime}(k)+\frac{f^{\prime}(k) \pi^{\prime}\left(\frac{\eta N f\left(k_{u}\right)}{\gamma}\right) \eta N}{\gamma} \frac{u\left(\frac{f(k)-\delta k}{1+\pi\left(\frac{\eta N f(k)}{\gamma}\right)}\right)-\frac{(f(k)-\delta k) u^{\prime}\left(\frac{f(k)-\delta k}{1+\pi\left(\frac{\eta N f(k)}{\gamma}\right)}\right)}{1+\pi\left(\frac{\eta N f(k)}{\gamma}\right)}}{u^{\prime}\left(\frac{f(k)-\delta k}{1+\pi\left(\frac{\eta N f(k)}{\gamma}\right)}\right)}=\delta
$$

Its RHS is a horizontal line at $\delta$. From the existence conditions, we have that $\phi(k)>\delta$ when $k \rightarrow 0$ and that $\phi(k)<\delta$ when $k \rightarrow+\infty$. Hence, the strict monotonicity of the LHS in $k$ guarantees that $\phi(k)=\delta$ for a unique level of $k$. The monotonicity condition is $\phi^{\prime}(k)<0 \forall k$. This can be written as:

$$
\begin{aligned}
& f^{\prime \prime}(k)+f^{\prime \prime}(k) \pi^{\prime}\left(\frac{\eta N f(k)}{\gamma}\right) \frac{\eta N \Lambda}{\gamma} \\
& +f^{\prime}(k)\left[\pi^{\prime \prime}\left(\frac{\eta N f(k)}{\gamma}\right) \frac{\eta N f^{\prime}(k)}{\gamma} \frac{\eta N \Lambda}{\gamma}+\pi^{\prime}\left(\frac{\eta N f(k)}{\gamma}\right) \frac{\eta N}{\gamma} \frac{d \Lambda}{d k}\right] \\
< & 0
\end{aligned}
$$

with

$$
\Lambda \equiv \frac{\left[u\left(\frac{f(k)-\delta k}{1+\pi\left(\frac{\eta N f(k)}{\gamma}\right)}\right)-\frac{f(k)-\delta k}{1+\pi\left(\frac{\eta N f(k)}{\gamma}\right)} u^{\prime}\left(\frac{f(k)-\delta k}{1+\pi\left(\frac{\eta N f(k)}{\gamma}\right)}\right)\right]}{u^{\prime}\left(\frac{f(k)-\delta k}{1+\pi\left(\frac{\eta N f(k)}{\gamma}\right)}\right)}
$$

As shown in Proposition 2, the mere concavity of the production function $f^{\prime \prime}(k)<0$ does not suffice, in the present context, to guarantee that the conditions of Proposition 1 fully identify the utilitarian social optimum. The reason why those conditions do not suffice lies in the fact that the survival probability varies with capital accumulation. To see this, note that, if $\pi^{\prime}(\cdot)=0$, the mere condition $f^{\prime \prime}(k)<0$ would suffice to guarantee that the conditions stated in Proposition 1 identify the utilitarian social optimum.

Having examined the existence and uniqueness of the utilitarian social optimum, let us now focus on a particular feature of that social optimum. At the utilitarian optimum, a proportion $\pi\left(P_{u}\right)$ of each cohort will turn out to have a long life, whereas a proportion $1-\pi\left(P_{u}\right)$ of each cohort will turn out to have a short life, and will thus not enjoy the old age.

Those inequalities in longevity can lead to substantial inequalities in terms of realized lifetime well-being. To see this, note that the realized lifetime well-being of long-lived individuals is equal, at the utilitarian social optimum, to:

$$
U^{l l}=u\left(c_{u}\right)+u\left(d_{u}\right)=2 u\left(c_{u}\right)
$$

On the contrary, the realized lifetime well-being of short-lived individuals is:

$$
U^{s l}=u\left(c_{u}\right)
$$


Hence, short-lived individuals are, at the utilitarian social optimum, worstoff than long lived individuals when:

$$
u\left(c_{u}\right)>0 \Longleftrightarrow c_{u}>\bar{c}
$$

Using the resource constraint at the utilitarian social optimum, that condition can be written as:

$$
f\left(k_{u}\right)-\delta k_{u}>\bar{c}\left[1+\pi\left(\frac{\eta N f\left(k_{u}\right)}{\gamma}\right)\right]
$$

That condition is quite weak, since the neutral consumption level for continuing existence $\bar{c}$ is usually quite low. Note that the gap in realized lifetime well-being $u\left(c_{u}\right)$ is decreasing with the level of $\pi(\cdot)$. Thus, the more noxious the production process is (the higher $\eta$ is), the lower the proportion of survivors, and the larger the gap in realized lifetime well-being $u\left(c_{u}\right)$ is. The extent of well-being inequality at the utilitarian social optimum is also increasing with the cohort size $N$, but is decreasing with the natural rate of pollution absorption $\gamma$.

\section{The ex post egalitarian optimum}

Utilitarianism tends, in the present context, to lead to significant inequalities in realized lifetime well-being between short-lived and long-lived individuals. Those inequalities are not easy to justify. Actually, in our economy, all individuals are exactly identical ex ante, that is, before the duration of their life is revealed. All individuals contribute, through the production process, to the pollution. However, despite those common features, some individuals will turn out to be short-lived, whereas others will, despite the pollution, enjoy the old age. Thus, although all individuals are identical ex ante, there will be significant inequalities in longevity and in realized lifetime well-being.

Given that the unlucky short-lived individuals can hardly be regarded as responsible for this, it makes sense to try to make those inequalities in realized lifetime well-being as small as possible. Actually, as highlighted by Fleurbaey (2008), inequalities due to circumstances - as opposed to inequalities for which individuals can be regarded as responsible - should be minimized. This objective is the one of the ex post egalitarian social planner. The problem of the ex post egalitarian social planner consists in selecting levels of consumptions, capital

and pollution in such a way as to maximize the realized lifetime well-being of the unlucky short-lived, while respecting the resource constraint of the economy.

Given that all members of a cohort are exactly identical ex ante (i.e. shortlived and long-lived cannot be distinguished by the planner), the egalitarian social planning problem can be written as:

$$
\begin{aligned}
& \max _{c, d, k, P} \min \{u(c), u(c)+u(d)\} \\
& \text { s.t. } f(k)-\delta k=c+d \pi(P) \\
& \text { s.t. } P=\frac{\eta N f(k)}{\gamma}
\end{aligned}
$$


The objective function is continuous, but not differentiable. This objective function is thus hardly tractable, but the social planning problem can be rewritten in a different way. Actually, the condition $u(d)=0$ is necessary and sufficient to achieve the equalization of lifetime well-being levels across all individuals in a cohort. In the light of that condition, it is possible to rewrite the ex post egalitarian social planning problem in a simpler form, as the maximization of first-period consumption subject to the resource constraint, and subject to the egalitarian constraint that the lifetime welfare of long-lived individuals is not inferior to the lifetime well-being of short-lived individuals, that is, $u(c)+u(d) \geq u(c) .{ }^{9}$ Hence the ex post egalitarian social planning problem can be rewritten by means of the following Lagrangian:

$$
\max _{c, d, k} u(c)+\lambda\left[f(k)-\delta k-c-d \pi\left(\frac{\eta N f(k)}{\gamma}\right)\right]+\mu u(d)
$$

where $\lambda$ is the Lagrange multiplier associated with the resource constraint, and $\mu$ is the Lagrange multiplier associated with the egalitarian constraint. The FOCs are:

$$
\begin{aligned}
u^{\prime}(c) & =\lambda \\
\mu u^{\prime}(d) & =\lambda \pi\left(\frac{\eta N f(k)}{\gamma}\right) \\
\lambda\left[f^{\prime}(k)-\delta-d \pi^{\prime}\left(\frac{\eta N f(k)}{\gamma}\right) \frac{\eta N f^{\prime}(k)}{\gamma}\right] & =0
\end{aligned}
$$

as well as:

$$
\begin{aligned}
& \lambda \geq 0, f(k)-\delta k \geq c+d \pi\left(\frac{\eta N f(k)}{\gamma}\right) \\
& \mu \geq 0, u(d) \geq 0
\end{aligned}
$$

with complementary slackness.

The egalitarian condition can only be satisfied provided $u(d)=0$, implying that second-period consumption equals $\bar{c}$. Regarding the optimal level of $k$, the FOC can be rewritten as:

$$
f^{\prime}(k)=\delta+\bar{c} \pi^{\prime}\left(\frac{\eta N f(k)}{\gamma}\right) \frac{\eta N f^{\prime}(k)}{\gamma}
$$

Given that the second term of the RHS is negative, it follows that $f^{\prime}(k)<$ $\delta$. Thus the optimal level of $k$ at the egalitarian social optimum is higher than under the standard Golden Rule, and also higher than at the utilitarian optimum. The intuition behind that result goes as follows. From the perspective of maximizing the well-being of the unlucky short-lived, the pollution caused by the accumulation of capital is a way to extent consumption possibilities for the

\footnotetext{
${ }^{9}$ Clearly, if long-lived agents were worst-off than short-lived agents, maximizing the wellbeing of the short-lived would not make sense.
} 
young, by reducing the inactive/active ratio. Note that the size of that effect depends on the level of the neutral consumption for continuing existence $\bar{c}$. The higher it is, the higher the optimal capital should be.

An important corollary of this concerns the socially optimal level of pollution. Given that the optimal $k$ is higher under ex post egalitarianism than under utilitarianism, the optimal level of $P$ is also higher under ex post egalitarianism. That result may look surprising at first glance, but it is actually quite intuitive once it is understood that the size of first-period consumption - the unique source of well-being for unlucky short-lived persons - is limited by the size of aggregate old-age consumption enjoyed by the lucky long-lived. Thus, from an egalitarian perspective, pollution is a way to expand the consumption possibilities of the unlucky. Proposition 3 summarizes our results.

Proposition 3 If

$$
\lim _{k \rightarrow+\infty} f^{\prime}(k)=0
$$

and if

$$
\lim _{k \rightarrow 0}\left[f^{\prime}(k)-\bar{c} \pi^{\prime}\left(\frac{\eta N f(k)}{\gamma}\right) \frac{\eta N f^{\prime}(k)}{\gamma}\right]>\delta
$$

an interior ex post egalitarian social optimum $\left\{c_{e}, d_{e}, k_{e}, P_{e}\right\}$ exists and satisfies:

$$
\begin{aligned}
c_{e} & =f\left(k_{e}\right)-\delta k_{e}-\bar{c} \pi\left(P_{e}\right) \\
d_{e} & =\bar{c} \\
f^{\prime}\left(k_{e}\right) & =\delta+\bar{c} \pi^{\prime}\left(P_{e}\right) \frac{\eta N f^{\prime}\left(k_{e}\right)}{\gamma} \\
P_{e} & =\frac{\eta N f\left(k_{e}\right)}{\gamma}
\end{aligned}
$$

In comparison with the utilitarian social optimum (and assuming $u\left(d_{u}\right)-$ $\left.d_{u} u^{\prime}\left(d_{u}\right)>0\right)$, we have:

$$
\begin{aligned}
c_{u} & \gtrless c_{e} \\
d_{u} & >d_{e}=\bar{c} \\
k_{u} & <k_{e} \\
P_{u} & <P_{e}
\end{aligned}
$$

Proof. Let us rewrite the FOC for an interior optimal level of $k$ as:

$$
\varphi(k) \equiv f^{\prime}(k)-\bar{c} \pi^{\prime}\left(\frac{\eta N f(k)}{\gamma}\right) \frac{\eta N f^{\prime}(k)}{\gamma}=\delta
$$

We have:

$$
\begin{aligned}
\lim _{k \rightarrow+\infty} \varphi(k) & =0-\bar{c} \pi^{\prime}\left(\frac{\eta N f(k)}{\gamma}\right) 0=0<\delta \\
\lim _{k \rightarrow 0} \varphi(k) & =f^{\prime}(0)-\bar{c} \pi^{\prime}\left(\frac{\eta N f(0)}{\gamma}\right) \frac{\eta N f^{\prime}(0)}{\gamma}
\end{aligned}
$$


Hence, assuming

$$
\lim _{k \rightarrow 0}\left[f^{\prime}(k)-\bar{c} \pi^{\prime}\left(\frac{\eta N f(k)}{\gamma}\right) \frac{\eta N f^{\prime}(k)}{\gamma}\right]>\delta
$$

suffices to guarantee the existence of an interior optimal level of $k$. The rest follows from the FOCs. The last part comes from comparing the FOCs for $k$ in the two planning problems. Under utilitarianism, we have, under $u\left(d_{u}\right)-$ $d_{u} u^{\prime}\left(d_{u}\right)>0$ :

$$
f^{\prime}\left(k_{u}\right)=\delta-\pi^{\prime}\left(\frac{\eta N f\left(k_{u}\right)}{\gamma}\right) \frac{\eta N f^{\prime}\left(k_{u}\right)}{\gamma} \frac{\left[u\left(d_{u}\right)-d_{u} u^{\prime}\left(d_{u}\right)\right]}{u^{\prime}\left(d_{u}\right)}>\delta
$$

while under ex post egalitarianism, we have:

$$
f^{\prime}\left(k_{e}\right)=\delta+\bar{c} \pi^{\prime}\left(\frac{\eta N f\left(k_{e}\right)}{\gamma}\right) \frac{\eta N f^{\prime}\left(k_{e}\right)}{\gamma}<\delta
$$

Hence it must be the case that $k_{u}<k_{e}$. Moreover, under $u\left(d_{u}\right)-d_{u} u^{\prime}\left(d_{u}\right)>0$, we have $d_{u}>\bar{c}=d_{e}$. The rest follows from the FOCs.

Proposition 3 states that the interior ex post egalitarian optimum exhibits, in general, a higher level of capital than at the utilitarian optimum, as well as a higher pollution level. The reason why ex post egalitarianism leads to a higher long-run pollution level lies in the fact that pollution allows for the widening of the consumption possibilities at the young age, which is what matters for compensating the unlucky short-lived individuals. Those larger consumption possibilities at the young age come from the effect of pollution on the age structure of the population. Pollution increases the active/inactive ratio, and, hence, increase the consumption possibilities at the young age. This mechanism can be called the "age-structure effect".

Moreover, the shape of the consumption profile differs quite a lot from the one prevailing at the utilitarian optimum. The consumption profile was flat under utilitarianism, but it is now, under general conditions, decreasing with the age. The underlying intuition is, here again, to minimize inequalities in realized lifetime well-being between the short-lived and the long-lived.

Whereas Proposition 3 gives us conditions under which some quartet $\{c, d, k, P\}$ satisfies the optimality conditions associated with an interior ex post egalitarian optimum, it is possible that several quartets $\{c, d, k, P\}$ satisfy those conditions. Proposition 4 identifies the conditions under which one and only one quartet $\{c, d, k, P\}$ satisfies those optimality conditions.

Proposition 4 Suppose that, for all $k>0$, we have:

$$
f^{\prime \prime}(k)-\bar{c}\left[\pi^{\prime \prime}\left(\frac{\eta N f(k)}{\gamma}\right) \frac{\eta N f^{\prime}(k)}{\gamma} \frac{\eta N f^{\prime}(k)}{\gamma}+\pi^{\prime}\left(\frac{\eta N f(k)}{\gamma}\right) \frac{\eta N f^{\prime \prime}(k)}{\gamma}\right]<0
$$

then there exists a unique quartet $\left\{c_{e}, d_{e}, k_{e}, P_{e}\right\}$ satisfying the conditions associated with the ex post egalitarian social optimum. 
Proof. Take the FOC for optimal $k$ :

$$
\varphi(k) \equiv f^{\prime}(k)-\bar{c} \pi^{\prime}\left(\frac{\eta N f(k)}{\gamma}\right) \frac{\eta N f^{\prime}(k)}{\gamma}=\delta
$$

From the existence conditions, we have that $\varphi(k)>\delta$ when $k \rightarrow 0$ and that $\varphi(k)<\delta$ when $k \rightarrow+\infty$. Hence, the strict monotonicity of the LHS in $k$ guarantees that $\varphi(k)=\delta$ for a unique level of $k$. The monotonicity condition is $\varphi^{\prime}(k)<0 \forall k$. This can be written as:

$\varphi^{\prime}(k)=f^{\prime \prime}(k)-\bar{c}\left[\pi^{\prime \prime}\left(\frac{\eta N f(k)}{\gamma}\right) \frac{\eta N f^{\prime}(k)}{\gamma} \frac{\eta N f^{\prime}(k)}{\gamma}+\pi^{\prime}\left(\frac{\eta N f(k)}{\gamma}\right) \frac{\eta N f^{\prime \prime}(k)}{\gamma}\right]<0$

If the survival probability was constant (i.e. $\pi^{\prime}(\cdot)=0$ ), the concavity of $f(k)$ would suffice to guarantee that there exists only one local maximum, which is also the global one. But given $\pi^{\prime}(\cdot)<0$, this condition is not sufficient to guarantee that only one quartet $\{c, d, k, P\}$ satisfies the properties stated in Proposition 3.

In sum, adopting the ex post egalitarian social objective instead of the standard utilitarian objective affects significantly the form of the long-run social optimum, in particular regarding the optimal level of pollution. Once the goal is to maximize the realized lifetime well-being of the unlucky short-lived, the optimal level of pollution becomes larger. The intuition behind this result lies in the impact of pollution on the age structure of the population, and, hence, on the consumption possibilities at the young age.

\section{$5 \quad$ Health expenditures}

Up to now, we considered an economy where survival conditions are entirely determined by the extent of pollution. Whereas pollution is a major determinant of longevity, one may want to check whether our results are robust to considering a more general survival function, where survival would depend not only on pollution, but, also, on health expenditures. This section explores whether our previous results are robust to the postulated survival function.

Survival conditions We now assume that the survival probability $\pi_{t+1}$ depends not only on pollution $P_{t}$, but, also, on health spending per worker, denoted by $h_{t}$. Those health spending are spent when individuals are working. Hence, one can regard these expenditures as preventive health spending, in the sense that those expenditures increase, ceteris paribus, the survival chances of each individual:

$$
\pi_{t+1}=\pi\left(P_{t}, h_{t}\right)
$$

with $\pi_{P}<0, \pi_{P P}<0, \pi_{h}>0, \pi_{h h}<0$ and $\pi_{h P}>0$. This last assumption states that the positive impact of preventive health spending on survival chances is higher when the prevailing pollution level is higher. 
Resource constraint Once health expenditures are introduced, the resource constraint becomes:

$$
F\left(K_{t}, L_{t}\right)=c_{t} L_{t}+h_{t} L_{t}+d_{t} \pi\left(P_{t-1}, h_{t-1}\right) L_{t-1}+K_{t+1}-(1-\delta) K_{t}
$$

At the steady-state and in intensive terms, that condition becomes:

$$
f(k)-\delta k=c+h+d \pi(P, h)
$$

\subsection{The utilitarian optimum revisited}

The utilitarian social planning problem becomes:

$$
\begin{aligned}
& \max _{c, d, h, k, P} u(c)+\pi(P, h) u(d) \\
& \text { s.t. } f(k)-\delta k=c+h+d \pi(P, h) \\
& \text { s.t. } P=\frac{\eta N f(k)}{\gamma} \\
& \text { s.t. } h \geq 0
\end{aligned}
$$

That problem can be rewritten by means of the following Lagrangian:

$$
\max _{c, d, h, k} u(c)+\pi\left(\frac{\eta N f(k)}{\gamma}, h\right) u(d)+\lambda\left[f(k)-\delta k-c-h-d \pi\left(\frac{\eta N f(k)}{\gamma}, h\right)\right]+\chi h
$$

The FOCs are

$$
\begin{aligned}
u^{\prime}(c) & =\lambda \\
\pi\left(\frac{\eta N f(k)}{\gamma}, h\right) u^{\prime}(d) & =\lambda \pi\left(\frac{\eta N f(k)}{\gamma}, h\right) \\
-\frac{\eta N f^{\prime}(k)}{\gamma} \pi_{P}\left(\frac{\eta N f(k)}{\gamma}, h\right) u(d) & =\lambda\left[f^{\prime}(k)-\delta-d \pi_{P}\left(\frac{\eta N f(k)}{\gamma}, h\right) \frac{\eta N f^{\prime}\left(k_{3}\right)}{\gamma}(33)\right] \\
\pi_{h}\left(\frac{\eta N f(k)}{\gamma}, h\right) u(d)+\chi & =\lambda\left[1+d \pi_{h}\left(\frac{\eta N f(k)}{\gamma}, h\right)\right]
\end{aligned}
$$

as well as the conditions

$$
\begin{aligned}
& \lambda \geq 0, f(k)-\delta k-c-h-d \pi\left(\frac{\eta N f(k)}{\gamma}, h\right) \geq 0 \\
& \chi \geq 0, h \geq 0
\end{aligned}
$$

with complementary slackness.

From the FOCs for consumption, it follows that the utilitarian optimum still involves here flat consumption profiles: $c=d$. Turning now to the FOC for optimal $k$, note that this can be rewritten as:

$$
f^{\prime}(k)=\delta-\frac{\eta N f^{\prime}(k)}{\gamma} \pi_{P}\left(\frac{\eta N f(k)}{\gamma}, h\right)\left[\frac{u(d)-d u^{\prime}(d)}{u^{\prime}(d)}\right]
$$


That condition is quite similar to the one derived in Section 3. The unique difference lies in the fact that the marginal impact of capital on survival conditions is affected by the level of health spending $h$. Consider now the FOC for health spending, which can be rewritten as:

$$
\pi_{h}\left(\frac{\eta N f(k)}{\gamma}, h\right) u(d)+\chi=u^{\prime}(c)\left[1+d \pi_{h}\left(\frac{\eta N f(k)}{\gamma}, h\right)\right]
$$

That condition states that there exists an interior optimal health spending $h$ only if there exists some $h$ such that the marginal social welfare gain from investing in health, equal to $\pi_{h}\left(\frac{\eta N f(k)}{\gamma}, h\right) u(d)$, is exactly equal to the marginal social welfare loss from investing in health, i.e. $u^{\prime}(c)\left[1+d \pi_{h}\left(\frac{\eta N f(k)}{\gamma}, h\right)\right]$, yielding $\chi=0$. That loss depends on the foregone consumption at the young age, and on the foregone consumption at the old age, due to a higher proportion of retirees. That condition holds if and only if, for some $h>0$, we have:

$$
u^{\prime}(c)=\pi_{h}\left(\frac{\eta N f(k)}{\gamma}, h\right)\left[u(d)-u^{\prime}(d) d\right]
$$

Given that $\left[u(d)-u^{\prime}(d) d\right]$ is positive in an economy with large production capacity, this condition is likely to be satisfied, yielding an interior optimal level for $h$. Note, however, that, in poor economies with limited production capacity, it may be the case that the optimal $d$ is below the neutral level $\bar{c}$, leading to a corner solution in health spending, i.e. $h=0$.

Under an interior optimal level for $h$, the FOC for $k$ can be rewritten as:

$$
f^{\prime}(k)=\delta-\frac{\eta N f^{\prime}(k)}{\gamma} \frac{\pi_{P}\left(\frac{\eta N f(k)}{\gamma}, h\right)}{\pi_{h}\left(\frac{\eta N f(k)}{\gamma}, h\right)}
$$

That alternative formulation makes appear the central role played by the form of the survival function $\pi(P, h)$. If the derivative of $\pi(P, h)$ with respect to $P$ is, in absolute value, small in comparison to the derivative of $\pi(P, h)$ with respect to the amount of health spending $h$, then the second term of the RHS is likely to be quite small, so that the optimal $k$ is then almost equal to its value according to the standard Golden Rule. In the opposite case, the optimal $k$ remains close to the one derived in Section 3. Proposition 5 summarizes our results.

Proposition 5 An interior utilitarian optimum is a quintet $\left\{c_{u}, d_{u}, h_{u}, k_{u}, P_{u}\right\}$ satisfying the conditions:

$$
\begin{aligned}
c_{u} & =d_{u} \\
f^{\prime}\left(k_{u}\right) & =\delta-\frac{\eta N f^{\prime}\left(k_{u}\right)}{\gamma} \frac{\pi_{P}\left(P_{u}, h_{u}\right)}{\pi_{h}\left(P_{u}, h_{u}\right)} \\
u^{\prime}\left(c_{u}\right) & =\pi_{h}\left(P_{u}, h_{u}\right)\left[u\left(d_{u}\right)-u^{\prime}\left(d_{u}\right) d_{u}\right] \\
f\left(k_{u}\right)-\delta k_{u} & =c_{u}+h_{u}+d_{u} \pi\left(P_{u}, h_{u}\right) \\
P_{u} & =\frac{\eta N f\left(k_{u}\right)}{\gamma}
\end{aligned}
$$


Proof. See the above FOCs.

Proposition 5 suggests that the introduction of health spending does not affect the key features of the utilitarian social optimum. ${ }^{10}$ First, the optimal consumption profile remains flat, as in the framework without health spending. This means that, from a utilitarian point of view, the financial effort due to health investment is spread equally across life-periods. Regarding the optimal capital accumulation, the associated optimal capital level differs, depending on the form of the survival function. In the case, mentioned in the above discussion, where $\left|\pi_{P}\left(P_{u}, h_{u}\right)\right|$ is small with respect to $\pi_{h}\left(P_{u}, h_{u}\right)$, the optimal capital level is now higher than in the baseline model. As a consequence of this, the optimal pollution level is also higher than in the absence of health spending. On the contrary, if $\pi_{h}\left(P_{u}, h_{u}\right)$ is small in comparison to $\left|\pi_{P}\left(P_{u}, h_{u}\right)\right|$, the optimal pollution will remain close to the one derived in Section 3.

Finally, it is worth emphasizing that, as in the baseline model, the utilitarian social optimum is characterized by significant inequalities in realized lifetime well-being between short-lived and long-lived individuals. If one uses the resource constraint, the welfare gap can be written as:

$$
U^{l l}-U^{s l}=u\left(\frac{f\left(k_{u}\right)-\delta k_{u}-h_{u}}{1+\pi\left(P_{u}, h_{u}\right)}\right)
$$

It is not straightforward to see whether inequalities in lifetime well-being are here larger or smaller than before. This depends strongly on the form of the survival function $\pi\left(P_{u}, h_{u}\right)$.

\subsection{The egalitarian optimum revisited}

Whereas the extent to which the introduction of health spending affects inequalities is ambiguous, those inequalities remain, in the present setting, as hard to justify as in the framework without health spending. Actually, in the extended model, individuals remain exactly equal ex ante, but, ex post, a fraction $\pi\left(P_{u}, h_{u}\right)$ of them will enjoy the old age, whereas a fraction $1-\pi\left(P_{u}, h_{u}\right)$ will die before reaching retirement. That differential treatment remains, as in the baseline model, quite arbitrary. Hence, an egalitarian social planner focusing on realized individual achievements would like to minimize those inequalities.

Let us examine how the introduction of health spending affects the ex post egalitarian optimum. In the presence of health spending, that problem becomes:

$$
\begin{aligned}
& \max _{c, d, k, h, P} \min \{u(c), u(c)+u(d)\} \\
& \text { s.t. } f(k)-\delta k=c+h+d \pi(P, h) \\
& \text { s.t. } P=\frac{\eta N f(k)}{\gamma} \\
& \text { s.t. } h \geq 0
\end{aligned}
$$

\footnotetext{
${ }^{10}$ Given that we are concerned here with the robustness of the comparison of optimal pollution levels under the two social optima, we will not discuss here the existence of an interior optimum. Moreover, we will also suppose that only one quintet $\{c, d, h, k, P\}$ satisfies the optimality conditions, and leave discussions on local vs global maximum aside.
} 
The objective function is non differentiable. However, as in the baseline model, we can rewrite that problem as the maximization of first-period consumption subject to the resource constraint, and subject to the egalitarian constraint that the lifetime welfare of long-lived individuals is not inferior to the lifetime well-being of short-lived individuals, that is, $u(c)+u(d) \geq u(c)$.

That problem can be rewritten by means of the following Lagrangian:

$$
\max _{c, d, h, k} u(c)+\lambda\left[f(k)-\delta k-c-h-d \pi\left(\frac{\eta N f(k)}{\gamma}, h\right)\right]+\mu u(d)+\chi h
$$

FOCs of that problem are:

$$
\begin{aligned}
u^{\prime}(c) & =\lambda \\
\lambda \pi\left(\frac{\eta N f(k)}{\gamma}, h\right) & =\mu u^{\prime}(d) \\
f^{\prime}(k) & =\delta+d \pi_{P}\left(\frac{\eta N f(k)}{\gamma}, h\right) \frac{\eta N f^{\prime}(k)}{\gamma} \\
\lambda\left(1+d \pi_{h}\left(\frac{\eta N f(k)}{\gamma}, h\right)\right) & =\chi
\end{aligned}
$$

as well as conditions

$$
\begin{aligned}
& \lambda \geq 0, f(k)-\delta k-c-h-d \pi\left(\frac{\eta N f(k)}{\gamma}, h\right) \geq 0 \\
& \mu \quad \geq 0, u(d) \geq 0 \\
& \chi \geq 0, h \geq 0
\end{aligned}
$$

with complementary slackness.

From the FOC for health spending, we see that the optimal health investment must be a corner solution. Indeed, that solution would be interior if the LHS of the FOC was equal to 0 , that is, if we had:

$$
\lambda\left(1+d \pi_{h}\left(\frac{\eta N f(k)}{\gamma}, h\right)\right)=0
$$

Using the FOC for $c$ and the FOC for $d$, that expression can be written as:

$$
u^{\prime}(c)+\mu u^{\prime}(d) d \frac{\pi_{h}\left(\frac{\eta N f(k)}{\gamma}, h\right)}{\pi\left(\frac{\eta N f(k)}{\gamma}, h\right)}=0
$$

That condition can never be achieved, since the two terms of the LHS are necessarily positive. Thus we must have $h=0$. The intuition behind that result goes as follows. Health spending allow for the increase in the proportion of survivors to the old age $\pi(P, h)$. However, for the unlucky agents who do not reach the old age, those health expenditures constitute a pure waste of resources, since those spending reduced their purchasing power at the young age. 
Regarding the consumption profile, the egalitarian constraint implies $u(d)=$ 0 , so that it must be the case that $d=\bar{c}$. Substituting for $h=0$ and $d=\bar{c}$ in the FOC for optimal capital, we obtain:

$$
f^{\prime}(k)=\delta+\bar{c} \pi_{P}\left(\frac{\eta N f(k)}{\gamma}, 0\right) \frac{\eta N f^{\prime}(k)}{\gamma}
$$

Let us compare that condition with the one prevailing under utilitarianism. As the second term of the RHS is negative, the optimal capital is here higher than under utilitarianism. To see this, remind that the FOC for optimal capital in the utilitarian problem was:

$$
f^{\prime}(k)=\delta-\frac{\eta N f^{\prime}(k)}{\gamma} \pi_{P}\left(\frac{\eta N f(k)}{\gamma}, h\right)\left[\frac{u(d)-d u^{\prime}(d)}{u^{\prime}(d)}\right]
$$

where the second term of the RHS is positive when $u(d)-d u^{\prime}(d)>0$. Thus, the optimal level of capital remains higher under the ex post egalitarian optimum than under the utilitarian optimum, even when health expenditures are introduced. A major corollary of that result consists of the higher pollution level at the ex post egalitarian optimum, in comparison to the utilitarian optimum.

Proposition 6 An ex post egalitarian optimum is a quintet $\left\{c_{e}, d_{e}, h_{e}, k_{e}, P_{e}\right\}$ satisfying the conditions:

$$
\begin{aligned}
c_{e} & =f\left(k_{e}\right)-\delta k_{e}-\bar{c} \pi\left(P_{e}, 0\right) \\
d_{e} & =\bar{c} \\
h_{e} & =0 \\
f^{\prime}\left(k_{e}\right) & =\delta+\bar{c} \pi_{P}\left(P_{e}, 0\right) \frac{\eta N f^{\prime}\left(k_{e}\right)}{\gamma} \\
P_{e} & =\frac{\eta N f\left(k_{e}\right)}{\gamma}
\end{aligned}
$$

In comparison with the utilitarian optimum (under $u\left(d_{u}\right)-d_{u} u^{\prime}\left(d_{u}\right)>0$ ), we have:

$$
\begin{aligned}
c_{u} & \gtrless c_{e} \\
d_{u} & >d_{e}=\bar{c} \\
h_{u} & >h_{e}=0 \\
k_{u} & <k_{e} \\
P_{u} & <P_{e}
\end{aligned}
$$

Proof. The proof of the first part follows from the FOCs discussed above. The proof of the second part is obtained by comparing the FOCs associated to the utilitarian problem with the FOCs associated to the egalitarian problem.

As shown by Proposition 6, our main results are robust to the introduction of preventive health spending. The optimal pollution level remains higher under 
the ex post egalitarian optimum than under the utilitarian optimum. Focusing on the well-being of the unlucky short-lived supports thus some rise in the level of pollution, in comparison with the utilitarian optimum. Although one may find this result counterintuitive, it should be reminded that, at the utilitarian optimum, we have a lower pollution level, but at the cost of substantial inequalities in lifetime well-being across individuals. On the contrary, under the ex post egalitarian optimum, the situation of the unlucky short-lived is the best that can be achieved given the structural parameters of the economy.

\section{Decentralization}

The present section is dedicated to the study of the decentralization of the two social optima considered in this paper. For that purpose, we will first characterize the long-run equilibrium prevailing at the laissez-faire. Then, in a second stage, we will examine the decentralization of the utilitarian social optimum and of the ex post egalitarian optimum.

\subsection{The laissez-faire}

Let us consider here a two-period OLG economy with competitive markets, including a perfect annuity market with actuarially fair returns. The laissezfaire keeps the major assumptions made throughout this paper, regarding the production technology, the survival process and the pollution process:

$$
\begin{aligned}
Y_{t} & =F\left(K_{t}, L_{t}\right) \\
\pi_{t+1} & =\pi\left(P_{t}, h_{t}\right) \\
P_{t} & =\eta F\left(K_{t}, L_{t}\right)+(1-\gamma) P_{t-1}
\end{aligned}
$$

Firms At the laissez-faire, competitive firms maximize their profits, so that production factors are paid at their marginal productivity:

$$
\begin{aligned}
& w_{t}=f\left(k_{t}\right)-k_{t} f^{\prime}\left(k_{t}\right) \\
& R_{t}=f^{\prime}\left(k_{t}\right)+1-\delta
\end{aligned}
$$

where $w_{t}$ is the wage rate, and $R_{t}$ is equal to 1 plus the interest rate.

Individuals At the laissez-faire, individuals select the levels of consumptions $c_{t}$ and $d_{t+1}$, as well as their health spending $h_{t}$, in such a way as to maximize their expected lifetime well-being subject to their budget constraints.

The preferences of individuals can be represented by a function having the expected utility form:

$$
u\left(c_{t}\right)+\pi\left(P_{t}, h_{t}\right) u\left(d_{t+1}\right)
$$

The first-period budget constraint is:

$$
w_{t}=c_{t}+h_{t}+s_{t}
$$


where $s_{t}$ is individual savings.

Under a perfect annuity market, the gross return on savings $\hat{R}_{t}$ is:

$$
\hat{R}_{t}=\frac{R_{t}}{\pi_{t}\left(P_{t-1}, h_{t-1}\right)}
$$

Hence the second-period budget constraint is:

$$
\frac{s_{t} R_{t+1}}{\pi_{t+1}\left(P_{t}, h_{t}\right)}=d_{t+1}
$$

From the two budget constraints, we obtain the following intertemporal budget constraint:

$$
w_{t}=c_{t}+h_{t}+\frac{\pi_{t+1}\left(P_{t}, h_{t}\right) d_{t+1}}{R_{t+1}}
$$

The individual's problem can be written as the following Lagrangian:

$$
\max _{c_{t}, d_{t+1}, h_{t}} u\left(c_{t}\right)+\pi\left(P_{t}, h_{t}\right) u\left(d_{t+1}\right)+\lambda\left[w_{t}-c_{t}-h_{t}-\frac{\pi_{t+1}\left(P_{t}, h_{t}\right) d_{t+1}}{R_{t+1}}\right]
$$

The FOCs are:

$$
\begin{aligned}
u^{\prime}\left(c_{t}\right) & =\lambda=R_{t+1} u^{\prime}\left(d_{t+1}\right) \\
\pi_{h}\left(P_{t}, h_{t}\right) u\left(d_{t+1}\right) & =\lambda\left[1+\frac{\pi_{h}\left(P_{t}, h_{t}\right) d_{t+1}}{R_{t+1}}\right]
\end{aligned}
$$

Using those FOCs, the optimal level of health spending satisfies:

$$
u^{\prime}\left(c_{t}\right)=\pi_{h}\left(P_{t}, h_{t}\right)\left[u\left(d_{t+1}\right)-u^{\prime}\left(d_{t+1}\right) d_{t+1}\right]
$$

The LHS is the marginal welfare loss from investing in health, while the RHS is the marginal welfare gain from investing in health.

Intertemporal equilibrium The intertemporal equilibrium is a sequence of prices, individual and aggregate variables satisfying all equilibrium conditions. Firms maximize their profits, leading to the two conditions (54) and (55), and individuals maximize their expected utility, leading to conditions (61) and (63). In addition, the capital stock equals savings plus the undepreciated capital:

$$
K_{t+1}=N s_{t}+(1-\delta) K_{t}
$$

The labor market clears:

$$
L_{t}=N
$$

The goods market clears:

$$
F\left(K_{t}, N\right)+(1-\delta) K_{t}=N c_{t}+N h_{t}+N \pi\left(P_{t}, h_{t}\right) d_{t}+K_{t+1}
$$

The dynamic equation for pollution holds (equation (53)).

At time 0 , the consumption of old agents satisfies:

$$
d_{0}=\frac{R_{0} s_{-1}}{\pi\left(P_{0}, h_{-1}\right)}
$$

We take as given the initial capital stock $K_{0}=N s_{-1}$, the initial pollution stock $P_{-1}$ and the initial health spending $h_{-1}$. 
Stationary equilibrium Let us, for the sake of our policy analysis, suppose that there exists a unique and stable stationary equilibrium. At the stationary equilibrium, and given the constancy of the cohort size, all aggregate and individual variables are constant. The resource constraint of the economy is, in intensive terms:

$$
f(k)-\delta k=c+h+\pi(P, h) d
$$

whereas pollution is equal to:

$$
P=\frac{\eta N f(k)}{\gamma}
$$

Profit maximization by competitive firms imply:

$$
\begin{aligned}
& w=f(k)-k f^{\prime}(k) \\
& R=f^{\prime}(k)+1-\delta
\end{aligned}
$$

Utility maximization by individuals imply

$$
\begin{aligned}
& u^{\prime}(c)=R u^{\prime}(d) \\
& u^{\prime}(c)=\pi_{h}(P, h)\left[u(d)-u^{\prime}(d) d\right]
\end{aligned}
$$

\subsection{Decentralization of the utilitarian optimum}

Remind that, at the utilitarian social optimum, we have:

$$
\begin{aligned}
\frac{u^{\prime}\left(c_{u}\right)}{u^{\prime}\left(d_{u}\right)} & =1 \\
f^{\prime}\left(k_{u}\right) & =\delta-\frac{\eta N f^{\prime}\left(k_{u}\right)}{\gamma} \frac{\pi_{P}\left(P_{u}, h_{u}\right)}{\pi_{h}\left(P_{u}, h_{u}\right)} \\
u^{\prime}\left(c_{u}\right) & =\pi_{h}\left(P_{u}, h_{u}\right)\left[u\left(d_{u}\right)-u^{\prime}\left(d_{u}\right) d_{u}\right]
\end{aligned}
$$

Comparing those FOCs with the ones prevailing at the laissez-faire, it can be shown that the decentralization of the long-run utilitarian optimum requires the design of an adequate $\operatorname{tax} \tau$ on capital income. The goal of that tax is to internalize pollution externalities. Under a tax $\tau$, the FOCs prevailing at the laissez-faire become:

$$
\begin{aligned}
u^{\prime}(c) & =(R-\tau) u^{\prime}(d) \\
u^{\prime}(c) & =\pi_{h}(P, h)\left[u(d)-u^{\prime}(d) d\right]
\end{aligned}
$$

The comparison of the FOC for savings with its counterpart at the utilitarian social optimum suggests that we need $\tau$ such that $R-\tau=1$. Given that, in a competitive economy, $R=f^{\prime}(k)+1-\delta$, the tax $\tau$ must satisfy:

$$
f^{\prime}(k)-\delta-\tau=0
$$


Given that, at the utilitarian optimum, we have:

$$
f^{\prime}\left(k_{u}\right)=\delta-\frac{\eta N f^{\prime}\left(k_{u}\right)}{\gamma} \frac{\pi_{P}\left(P_{u}, h_{u}\right)}{\pi_{h}\left(P_{u}, h_{u}\right)}
$$

it follows that the optimal tax must be equal to:

$$
\tau_{u}=-\frac{\eta N f^{\prime}\left(k_{u}\right)}{\gamma} \frac{\pi_{P}\left(P_{u}, h_{u}\right)}{\pi_{h}\left(P_{u}, h_{u}\right)}>0
$$

The optimal tax on capital income is strictly positive. Its level depends on the shape of the survival function, and, in particular, on the sensitivity of the survival probability to pollution and health spending at the utilitarian social optimum. The higher the ratio $\frac{\pi_{P}\left(P_{u}, h_{u}\right)}{\pi_{h}\left(P_{u}, h_{u}\right)}$ is, the higher the optimal tax on capital income is, since, in that case, pollution generates a larger externality, which thus requires a stronger correction. The optimal tax on capital income is, ceteris paribus, increasing in the extent to which production is noxious (parameter $\eta$ ), and decreasing with the natural rate of absorption (parameter $\gamma$ ), because a higher $\eta$ and a lower $\gamma$ increase the size of the negative externality associated to pollution. Moreover, $\tau_{u}$ is increasing with the size of each cohort $N$, since a larger population leads to a larger negative externality of pollution, and, hence, requires a higher correcting tax.

The tax $\tau_{u}$ cannot suffice, on its own, to decentralize the utilitarian social optimum. One also needs an intergenerational transfer device that leads to the optimal long-run capital level $k_{u}$. Since capital accumulation leads to more health-damaging pollution, the optimal capital level is here lower than under the standard Golden Rule, as discussed above. Once $\tau=\tau_{u}$ and $k=k_{u}$, it is easy to see that the decentralized level of health spending is also equal to its socially optimal level $h_{u}$. Hence no other fiscal instrument is needed to decentralize the long-run utilitarian social optimum.

Proposition 7 The utilitarian optimum can be decentralized by means of:

- a tax on capital income satisfying the condition:

$$
\tau_{u}=-\frac{\eta N f^{\prime}\left(k_{u}\right)}{\gamma} \frac{\pi_{P}\left(P_{u}, h_{u}\right)}{\pi_{h}\left(P_{u}, h_{u}\right)}>0
$$

- an intergenerational transfer device leading to:

$$
f^{\prime}\left(k_{u}\right)=\delta-\frac{\eta N f^{\prime}\left(k_{u}\right)}{\gamma} \frac{\pi_{P}\left(P_{u}, h_{u}\right)}{\pi_{h}\left(P_{u}, h_{u}\right)}
$$

Proof. See above.

Proposition 7 states that the utilitarian social optimum can be decentralized by means of a tax on capital income and by means of intergenerational transfers aimed at generating the socially optimal capital intensity. If one takes the utilitarian criterion as an intuitive social objective, then the policy instruments 
described in Proposition 7 constitute the optimal environmental policy. Note, however, that, under those fiscal instruments, some substantial inequalities in lifetime well-being remain between long-lived and short-lived individuals. The rest of this section aims at comparing the optimal policy under utilitarianism with the policy decentralizing the ex post egalitarian social optimum.

\subsection{Decentralization of the ex post egalitarian optimum}

Remind that, at the ex post egalitarian optimum, we have:

$$
\begin{aligned}
\frac{u^{\prime}\left(c_{e}\right)}{u^{\prime}\left(d_{e}\right)} & =\frac{\mu}{\pi\left(\frac{\eta N f(k)}{\gamma}, 0\right)} \\
f^{\prime}\left(k_{e}\right) & =\delta+\bar{c} \pi_{P}\left(P_{e}, 0\right) \frac{\eta N f^{\prime}\left(k_{e}\right)}{\gamma} \\
h_{e} & =0
\end{aligned}
$$

where $\mu$ denotes the shadow social value of relaxing the egalitarian constraint. When that constraint is binding, we have $\mu>0$ and $d_{e}=\bar{c}$.

Comparing those conditions with the ones prevailing at the laissez-faire, it is straightforward to see that the decentralization of the ex post egalitarian optimum requires the design of an adequate $\operatorname{tax} \tau$ on capital income. Given that $u^{\prime}(c)=(R-\tau) u^{\prime}(d)$ prevails at the laissez-faire, the optimal tax $\tau$ must here satisfy:

$$
R-\tau=\frac{\mu}{\pi\left(\frac{\eta N f(k)}{\gamma}, 0\right)}
$$

Given that, in a competitive economy, $R=f^{\prime}(k)+1-\delta$, the tax $\tau$ must satisfy:

$$
f^{\prime}(k)+1-\delta-\tau=\frac{\mu}{\pi\left(\frac{\eta N f(k)}{\gamma}, 0\right)}
$$

Hence, at the optimal capital level, which is such that $f^{\prime}\left(k_{e}\right)=\delta+\bar{c} \pi_{P}\left(P_{e}, 0\right) \frac{\eta N f^{\prime}\left(k_{e}\right)}{\gamma}$, the optimal tax must satisfy the condition:

$$
\tau_{e}=\bar{c} \pi_{P}\left(P_{e}, 0\right) \frac{\eta N f^{\prime}\left(k_{e}\right)}{\gamma}+\left(1-\frac{\mu}{\pi\left(\frac{\eta N f\left(k_{e}\right)}{\gamma}, 0\right)}\right)>0
$$

The first term of that expression is negative, while the sign of the second term is positive, since $\frac{u^{\prime}\left(c_{e}\right)}{u^{\prime}\left(d_{e}\right)}<1$. In order to interpret that expression, note that, in the absence of any pollution, we would have:

$$
\tau_{e}=1-\frac{\mu}{\pi\left(\frac{\eta N f\left(k_{e}\right)}{\gamma}, 0\right)}>0
$$

That tax on capital income has, in the absence of pollution, a unique role, which is to decentralize the optimal consumption profile. Clearly, in the absence 
of $\operatorname{tax}(\tau=0)$, individuals would, at the laissez-faire, smooth their consumption profiles $(c=d)$. This flat consumption profile does not coincide at all with the consumption profile prevailing at ex post egalitarian optimum, where the ratio $\frac{u^{\prime}\left(c_{e}\right)}{u^{\prime}\left(d_{e}\right)}=\frac{\mu}{\pi(\cdot)}<1$. Given that, at the ex post egalitarian optimum, second-period consumption is equal to $\bar{c}$, which is, in general, much lower than $c_{e}$, the ratio $\frac{\mu}{\pi(\cdot)}<1$ is likely to be very small. Hence, in that case, the optimal tax on capital income will be quite close - but inferior - to 1 . The optimal tax is thus, in that case, strictly positive. Actually, taxing capital income is a simple way to reduce individual savings, so as to maximize the well-being of the unlucky short-lived.

Consider now the additional impact of pollution. Once pollution exists and deteriorates survival conditions, the first term of the formula for $\tau_{e}$ is negative, and thus leads to a reduction of the optimal tax on capital income. The intuition behind that - somewhat surprising - result goes as follows. From an ex post egalitarian perspective, what matters is to promote consumption possibilities at the young age. Hence, pollution, by making the surviving inactive old relatively less numerous with respect to the active young, tends to expand consumption possibilities at the young age. This explains why pollution tends here to reduce the optimal level of the capital income tax. Thus, the impact of pollution on the age structure has here the effect of reducing the optimal capital income tax.

Given that this additional effect supports the subsidization - instead of the taxation - of capital income, the magnitude of the optimal level $\tau_{e}$ in the presence of pollution is ambiguous. Two opposite forces are at work. On the one hand, taxing capital income pushes individuals to save less, so that the chosen consumption profile becomes close to the decreasing consumption profile prevailing at the ex post egalitarian optimum. On the other hand, taxing capital income reduces pollution, which implies that the age-structure of the population becomes less favorable to the consumption possibilities of the young. Those two opposite forces determine the level of the optimal capital income tax. Note that the sign of $\tau_{e}$ is likely to be strictly positive, since $f^{\prime}(k)>0$ for any $k$ implies that $\left|\bar{c} \pi_{P}\left(P_{e}, 0\right) \frac{\eta N f^{\prime}\left(k_{e}\right)}{\gamma}\right|<\delta<1$. Hence the second term - the positive one in the tax formula is likely to exceed the first term - the negative one -, leading to a positive tax on capital income $\tau_{e}>0$.

Moreover, as in the decentralization of the utilitarian optimum, the optimal capital income tax does not suffice to decentralize the social optimum. Actually, the decentralization of the optimal capital intensity $k_{e}$ requires, here again, a device of intergenerational transfers. Given that the optimal capital per worker is higher under the ex post egalitarian optimum than under the utilitarian optimum, the system of intergenerational transfers must here be adapted to the level of capital that is to be decentralized.

Finally, let us now consider the decentralization of the optimal level of health spending. Substituting for $c=c_{e}, d=d_{e}=\bar{c}, \tau=\tau_{e}$ and for $k=k_{e}$ in the FOC for health investment at the laissez-faire yields:

$$
u^{\prime}\left(c_{e}\right)=\pi_{h}\left(P_{e}, h\right)\left[0-u^{\prime}(\bar{c}) \bar{c}\right]
$$


The LHS is strictly positive. The RHS of that relation is strictly negative. Hence that condition for an interior optimal $h$ cannot be satisfied. Thus, once the optimal consumption profile has been decentralized, the marginal welfare gain from investing in health becomes negative at the laissez-faire (RHS), and is always lower than the marginal welfare loss of investing in health (LHS). Hence, individuals opt for a corner level of health spending equal to zero. This coincides with the optimal health spending at the ex post egalitarian optimum. Therefore, no additional policy instrument is needed to decentralize the ex post egalitarian social optimum. Proposition 8 summarizes our results.

Proposition 8 The ex post egalitarian optimum can be decentralized by means of:

- a tax on capital income satisfying the condition:

$$
\tau_{e}=\bar{c} \pi_{P}\left(P_{e}, 0\right) \frac{\eta N f^{\prime}\left(k_{e}\right)}{\gamma}+\left(1-\frac{\mu}{\pi\left(\frac{\eta N f\left(k_{e}\right)}{\gamma}, 0\right)}\right)>0
$$

- an intergenerational transfer device leading to:

$$
f^{\prime}\left(k_{e}\right)=\delta+\bar{c} \pi_{P}\left(P_{e}, 0\right) \frac{\eta N f^{\prime}\left(k_{e}\right)}{\gamma}
$$

Proof. See above.

Propositions 7 and 8 show that the optimal tax on capital income vary significantly depending on the social objective. Obviously, the precise magnitudes of $\tau_{u}$ and $\tau_{e}$ depend on the particular functional forms postulated for $f(\cdot), \pi(\cdot)$ and $u(\cdot)$. However, since the reasons for intervening are different under the two social objectives, the optimal tax rates are also likely to differ substantially. Whereas $\tau_{u}$ is increasing with the sensitivity of the survival conditions to pollution (i.e. $\left.\pi_{P}(\cdot)\right), \tau_{e}$ is decreasing with that sensitivity. The intuition behind that result goes as follows. The utilitarian criterion assigns a significant weight to the increase of the proportion of individuals reaching the old age. From that perspective, a higher sensitivity of $\pi$ to pollution requires a higher tax on capital income, in order to reduce pollution and to increase life expectancy. On the contrary, the ex post egalitarian social objective is only concerned with increasing the consumption possibilities at the young age. From that alternative perspective, a higher sensitivity of $\pi$ to pollution supports a lower taxation of capital income, since this pollution favors a more pyramidal age-structure, which is more favorable to the compensation of the unlucky short-lived.

The comparison of $\tau_{u}$ and $\tau_{e}$ depends on the structure of individual preferences. The neutral level of consumption for continuing existence $\bar{c}$ plays an important role. When $\bar{c}$ is low (implying a high value assigned to survival by individuals), the optimal tax $\tau_{e}$ decentralizing the ex post egalitarian optimum is likely to be high, and higher than $\tau_{u}$. On the contrary, when $\bar{c}$ is high, the age-structure effect becomes more sizeable, making $\tau_{e}$ closer to $\tau_{u}$. 


\section{Conclusions}

Pollution is a major cause of mortality. It generates large inequalities in terms of human longevity and in terms of lifetime well-being. The goal of this paper was to compare the optimal public policy under two social objectives: on the one hand, the standard utilitarian social objective, and, on the other hand, the $e x$ post egalitarian social objective, which aims at maximizing the realized lifetime well-being of the worst-off.

For that purpose, we developed a two-period OLG model with capital accumulation, with pollution induced by production, and where pollution reduces life expectancy. Focusing on the long-run, we characterized the optimal stationary equilibrium under the two social welfare functions, and we examined their decentralization by means of simple fiscal instruments.

The comparison the first-best social optima showed that the optimal level of pollution is higher under the ex post egalitarian optimum than under the utilitarian optimum. The intuition behind that result lies in the fact that the ex post egalitarian social objective lays an exclusive emphasis on the extension of consumption possibilities at the young age of life. Those consumption possibilities depend on the active/inactive ratio, which is increasing with pollution. This age-structure effect explains why the optimal capital is larger under the ex post egalitarian optimum than under the utilitarian optimum, leading to a higher optimal level of pollution.

On the policy side, the decentralization of each social optimum requires intergenerational transfers aimed at obtaining the optimal capital level, as well as taxes on capital income. However, the determinants of optimal capital income taxes were shown to differ, depending on the underlying social objective. From the utilitarian point of view, taxing capital income is a way to make individuals internalize the negative externalities, in terms of life expectancy, associated to capital accumulation in a polluted economy. From the point of view of ex post egalitarianism, taxing capital income is justified on the grounds that it allows for the decentralization of the decreasing consumption profile associated with the egalitarian optimum.

All in all, the optimal policy in a polluted economy depends strongly on the underlying social welfare criterion. Whereas that result could be expected, the main contribution of this paper was to identify the various determinants of the optimal fiscal instruments to be used for the decentralization of the social optima under comparison. Obviously, the optimal level of fiscal instruments depends on the postulated functional forms for the production function, for preferences and for the survival function. However, our analytical findings suggest that different social welfare criteria lead to quite different optimal policies. How a society deals with its pollution remains, at the end of the day, a matter of social choice. 


\section{References}

Arrow, K. (1971). A utilitarian approach to the concept of equality in public expenditures. Quarterly Journal of Economics, 85: 409-415.

Balestra, C. \& Dottori, D. (2012). Aging society, health and the environment. Journal of Population Economics, 25(3): 1045-1076.

Becker, G., Philipson, T, \& Soares, R. (2005). The quantity and the quality of life and the evolution of world inequality. American Economic Review, 95: 277-291.

de la Croix, D. \& Michel, P. (2002). A Theory of Economic Growth. Dynamics and Policy in Overlapping Generations. Cambridge University Press, Cambridge.

Dinda, S. (2004). Environmental Kuznets Curve Hypothesis: A Survey. Ecological Economics, 49 (4): 431-455.

Finkelstein, M., Jerrett, M., DeLuca, P., Finkelstein, N., Verma, D., Chapman, K. \& Sears, M. (2003). Relation between income, air pollution an mortality: a cohort study. Canadian Medical Association Journal, 169: 397-402.

Fleurbaey, M. (2008). Fairness, Responsibility and Welfare. Oxford University Press, New-York.

Fleurbaey, M., Leroux, M.L., \& Ponthiere, G. (2014). Compensating the dead. Journal of Mathematical Economics, 51: 28-41.

Fleurbaey, M. \& Ponthiere, G. (2013). Prevention against equality? Journal of Public Economics, 103: 68-84.

Grossman, G. and Krueger, A. (1995). Economic growth and the environment. Quarterly Journal of Economics, 110 (2): 353-377.

John, A. \& Pecchenino, R. (1994). An overlapping generations model of growth and the environment. Economic Journal, 104: 1393-1410.

John, A., Pecchenino, R. \& Schimmelpfennig, S. \& Schreft, S. (1995). Short-lived agents and the long-lived environment. Scandinavian Journal of Economics, 102: 135-150.

Jouvet, P.A., Michel, P. \& Vidal, J.P. (2000). Intergenerational altruism and the environment. Scandinavian Journal of Economics,102 (1): 135-150.

Jouvet, P.A., Michel, P. \& Rotillon, G. (2005). Optimal growth with pollution. How to use pollution permits? Journal of Economic Dynamics and Control, 29 (9): 1597-1609.

Jouvet, P.A., Pestieau, P. \& Ponthiere, G. (2010). Longevity and environmental quality in an OLG model. Journal of Economics, 100 (3): 191-216.

Kinney, P. \& Ozkanyak, H. (1991). Associations of daily mortality and air pollution in Los Angeles county. Environmental Research, 54: 99-120.

Laden, F., Schwartz, J., Spelzer, F. \& Dockery, D. (2006). Reductions in fine particulate air pollution and mortality. Extended follow-up of the Harvard six cities study. American Journal of Respiratory and Critical Care Medicine, 173: 667-672.

Mariani, F., Pérez-Barahona, A. \& Raffin, N. (2010). Life expectancy and the environment. Journal of Economic Dynamics and Control, 34(4): 798-815.

Mirrlees, J. (1982). The economic uses of utilitarianism, in Sen, A. \& Williams, B. Utilitarianism and Beyond, Cambridge University Press, Cambridge.

Nakabayashi, M. (2010). Optimal tax rules and public sector efficiency with an externality in an overlapping generations model. Journal of Public Economics, 94 (11-12): 1028-1040.

Ono, T. (2002). The Effects of Emission Permits on Growth and the Environment. Environmental and Resource Economics, 21 (1): 75-87. 
Peng, R., Dominici, F., Pastor-Barriuso, R., Zeger, S. \& Samet, J. (2005). Seasonal Analyses of Air Pollution and Mortality in 100 US Cities, American Journal of Epidemiology, 161 (6): 585-594.

Phelps, E. (1961). The golden rule of accumulation: a fable for growthmen. American Economic Review, 51 (4): 793-814.

Sartor, F. (2002). Les déterminants environnementaux de la mortalité, dans Caselli, G., Vallin, J., Wunsch, G. (eds.) Démographie: Analyse et Synthèse. Volume III: Les déterminants de la mortalité, Editions de l'INED, Paris.

Sen, A. (1973). On Economic Inequality. Oxford University Press, New-York.

WHO (2014). 7 million deaths annually linked to air pollution, available online at http://www.who.int/phe/health_topics/outdoorair/databases/en/ 